\title{
HEAT OF MARS IS LOVE OF LIFE?! TWO WAYS TO LOOK AT MARS
}

\author{
S. K. Alavipanah ${ }^{\mathrm{a}}{ }^{*}$, S. Van Gasselt ${ }^{\mathrm{b}}$, N. J. Mulder ${ }^{\mathrm{c}}$, M. A. Nezammahalleh ${ }^{\mathrm{d}}$ \\ Dept. of Remote Sensing and GIS, Faculty of Geography, University of Tehran, Iran, \\ salavipa@ut.ac.ir \\ Dept. of Planetary, Faculty of Earth Sciences, Ferie University of Berlin, Germany \\ Stefanie.pott@fu-berlin.de \\ Dept. of Physics, Faculty of Science, University of Twentee, Netherlands \\ Nanno.j.mulder@gmail.com \\ Dept. of Physical Geography, Geomorphology, University of Tehran, Tehran, Iran \\ mnezammahalleh@ut.ac.ir
}

KEYWORDS: Temperature, Mars, Literature, Thermal Remote Sensing, Geological Features

\begin{abstract}
:
Earth and Mars travel in neighboring orbits around the sun. Both are rocky planets, but only the earth has the conditions to support life on. Is such a great difference due to their surface temperatures? It is obvious that the surface temperatures of these planets are governed by two factors of: (a) the amount of energy they receive from the sun and, (b) the composition of their atmospheres. If it is true, we must focus more on the Thermal Remote Sensing on Mars. Since heat is an important factor in any physical, chemical and biological study, it can be said that the heat in the form of love and psychological processes is effective for these studies. In study about life on another planet, not only the thermal characteristics are essential but love or passion in Scientists' efforts that are related to inner heat should also be considered. Therefore, in this paper we review the studies on Mars with the emphasis on the temperature. We consider science, art, literature, and technology as well as any things related to the heat including ice melting, volcanology, soil, morphology, and geothermal. As we believe that it must be bridged between mental and science gaps, shouldn't we make both the art and the science convergent? Therefore, we have used different scientific and art resources to make the role of heat in the Mars clear. We are seeking to answer the question whether the heat can be as a common factor in the researches.
\end{abstract}

\section{1- INTRODUCTION}

The heat as an important limiting factor is essential for life. If we think about life in Mars or other plants, the optimization in temperature must be taken into account. This optimization might be needed not only for DNA Molecules (Zhang et al, 2008; Liu et al, 2006) but also for the Earth biosphere (Rutherford et al., 2006; Sun et al., 2012). Alavipanah (2002) believes that the heat is an indicator of the world intelligence. The belief is based on the fact that all substances in a temperature above absolute zero emit electromagnetic waves. It means when in the reality matters have a temperature and any reaction with the matter might have a reaction as temperature (Zhang et al, 2006). As a fundamental thermodynamic quantity, temperature describes the state of matter and quantifies transport of heat. The purpose of thermal infrared Remote Sensing (RS) is to make sense of data produced with sensors that are not in physical contact with the objects under investigation (Alavipanah, 2003). "Making sense of" is related to the concepts of awareness and interpretation both of which are more in the domain of arts than that of science. Education is a booting-up process that requires motivation by curiosity and adding of knowledge to the knowledge already acquired (Nash, 2003). Old techniques for memorization including rhythm, poems and prose should not be ignored in the process. However, once a certain level of abstracted 'understanding' [quantum physics, chaos theory] is achieved, we should not hesitate to shed the 'lies to children', used to build up mature understanding (Mulder, 2011). Thermodynamic, space and times, make us, adults, aware of our part in the universe. Temperature is such an essential factor in understanding of all the physical, chemical and biological systems on earth and space that Kustas and Norman (1995) stated that it must be considered in any study involving earth sciences. The scientists continue to search for reliable ways to determine "surface temperature", because it (a) has influence on the growth, development and survival of vegetation and life (Sun, 2012) and, (b) is sensitive to the partitioning of energy and mass fluxes on the earth surface. Jensen (2005) identified two classes of variables that can be remotely sensed:

1) Variables that can be measured directly from RS data. A thermal infrared sensor can record the apparent temperature of the materials by measuring the radiant flux emitted from their surfaces.

2) The general groups of variables that may be remotely sensed as hybrid variables.

But a question may arise that how important is the role of heat on the Mars surface? Why and where? Finally we want to investigate the importance of thermal infrared RS data on the Mars surface.

\section{1-1- Concepts of Heat in ancient times}

Molana Rumi, a poet in $13^{\text {th }}$ century A. D. believes that fire has been put in trust in every substance of the nature as a deposit. It is the original factor in mankind, animal, plants and solid 
bodies. This may be interpreted as what we call thermal energy in modern science! (Alavipanah, 2009) He writes:

"It is the fire of love that struck the windpipe; It is the ardor of love that fell into wine.

The call out of the windpipe is of the fire and not wind May one who does not feel this fire be naught!"

We believe that heat in the past had been interpreted under the name and by the term of fire. Molana Rumi expresses the importance of heat and considers it as a factor to percept the entity, receives data and without any need to light it is possible for seeing. This may be found in what we say as "extracting information from non visible portion of thermal infrared spectrum".

Heraclitus says: fire is the origin and the perfect source for transformation (Alavipanah, 2009).

All things are exchanged for fire, and fire for all things, even as wares for gold and gold for wares.

(Heraclitus of Ephesus)

Again it is better to see the idea of Heraclitus in the ancient and then the new thermodynamic law. Hiersome Cardanus believed that the nature has saved some moderate heat in the sky, from which everything is born. He says undoubtedly fire (indicator of heat) is resulted from this essential heat as a part of the whole creation and as the effect of motions. Boerhaave, the physicists in the 18th century writes: "if you make a mistake in the analysis on the nature of fire (temperature indicator or fire), your mistake will be transmitted to other fields of Physics. This is because fire is the basic factor in all products of nature.

Another important question may arise here! If we do not consider heat in our research on Mars, have we made not a mistake? Why?!

What are the reasons that some astronomers believe that the life exists on the Mars?

\section{1-2- Heat of love for life in Mars!}

What is love? What is life? Why Mars? To search about Mars and the possibility of settlement on the planet is not it essential to consider the love? How human being can overcome the problem of Global warming on Earth? If we cannot solve the problem, how we can change the cold climate of Mars to provide a suitable condition for life? So first of all we must know more about thermal inertia on Mars surface.

It is to say in psychological point of view that heat as love is also an effective motion for human evolution. Although the role of fire (heat) on biological dimension of human is much clear, but we have not also been far able to perceive sensualities and other conducts of intellect. Iranian literature is replete with the word of love and heat with the mentioned sensualities like feeling, thoughts and passive actions like imagination, instincts, reminders, wills, joy, grief, fear, affection, greed, and other conducts of the intellect. So is not the heat an indicator of love? Or is not love the main source of Heat? When we are thinking, searching and working on Mars, do we not consume the heat energy? Do we not transform the heat energy into other types of energy?

\section{1-2- Mars color}

There were many reasons to expect life on Mars but one for ancient scientists was the apparent seasonal color changes on the surface of the planet. Mars is commonly referred to as the Red Planet. The rocks, soils and sky have a red or pink hue. The distinct color has been observed by Stargazers through history.
The ancient Egyptians named the planet Her Descher meaning the red one. Alavipanah (2007) stated that in some Iranian poems it can be found a meaningful concept or reason for that. For example, in our research for the primary concepts of colour, light and perception, we found the primary colors (RGB), now as especial elements in RS, in poems of Mowlana Rumi about 400 years before Newton prism experiment. He expresses the probability of color existence through hidden state of color at night (the lack of light). In another couplet, he stated the existence of the source of light, its reflection and also the visual perception of color amazingly (Alavipanah, 2009).

The genius Newton in 1672, made his "New Theory about light and colors" by his prism experiment (Duarte, 2003). Ideas of Newton helped launch the era of modern optics (Duarte, 2003). You will be unable to see green, red and blue colors unless you could see more than these three lights. It is not possible to see the color without the external light as in nights. Also the same applies to the color of inner imagination (possibly as infrared).

\section{2- THERMAL IMAGES IN MODERN RS}

Temperature is so important that it must be taken into account for study not only on the Earth, but also on the Mars and other planets. However, a question may arise that the role of temperature in which of the Mars or Earth is more important in terms of geologic and soil forming processes?

To extract reliable information from thermal images, an interpreter must understand many variables related to the heat (Alavipanah, 2007). The process of Mars image interpretation requires not only scientific knowledge but all of the background an interpreter has obtained through a lifetime on the earth (Marchant et al, 2007). The synergism of integrating scientific knowledge with real world experience permits the interpreter to develop heuristic rules of thumbs to extract useful information from the imagery. An image analyst should not interpret a thermal infrared image as if it were an aerial photograph or a typical image. Rather, the analyst must understand radiation of short wavelength energy, longer wavelength energy and their interaction, the analyst must also think thermally to study the role of art in thermal RS interpretation (Alavipanah, 2007). The surface of Mars has many geological features and geomorphologic patterns that have recognizable counterparts on Earth. Earth and Mars surface features and their activities are also different substantially.

The answer to the question how Earth and Mars differ and why these two planets evolved so differently might be found in the heat. Great success has been achieved in recent decades to apply thermal infrared data. This is confirmed by the abundant literature related to Disaggregation of Land Surface Temperature (DLST) from different journals and conference proceedings (Table 1).

Table 1: Relevant journals and conference proceedings that have published more than two papers related to DLST. The search was conducted on Jan. 5, 2012.

\begin{tabular}{ll}
\hline Journals & Number of papers \\
\hline Remote Sensing of Environment & 12 \\
IEEE Transactions on Geoscience & 11 \\
and Remote Sensing & \\
Proc. SPIE & 9 \\
International Journal of Remote & 9 \\
Sensing & \\
IGARSS 5 & 9 \\
International Journal of Applied & \\
Earth Observation and & \\
\hline
\end{tabular}




\begin{tabular}{ll}
\hline Geoinformation 4 & 4 \\
Science in China & 4 \\
IEEE Geoscience and Remote & 3 \\
Sensing Letters & \\
Sensors 3 & 3 \\
Photogrammetric Engineering and & \\
Remote Sensing & 2 \\
\hline
\end{tabular}

\section{3- LITERATURE STATUS}

In order to investigate the role of heat in the evolution of phenomena, it is necessary to find their relationships through the developments of the thought of fire from the far-off past to the present. In this study, much literacy, religious and historical perspectives are compared with present human findings.

Mars surface is quite bare and devoid of organic matter, a dry soil condition in one hand and clear sky on the other, so it might be an ideal place for RS studies especially for some spectral ranges with the minimum absorption. This study reviews the published papers by RS data on the Mars surface and categorizes the studies theoretically at the optical, thermal and other electromagnetic spectrum. Prior to a survey of the literature of thermal RS on Mars, we provide the literature citations on Mars. Do the citations offer the inheritance relationship between the temperature and obtained information content on Mars? Do the optical sensors that are used for getting information of Mars surface are sufficient for future studies?

\section{4- CONTRIBUTION OF HEAT IN MARS}

\section{4-1- Mars Surface}

The rocky and dry surface of Mars is covered by soils rich in iron. There are lots of morphologies on the Mars surface including plains, valleys, volcanoes, and polar ice. There are also holes on the surface that rarely can be found on the earth.

\section{4-2- Mars geologic evolution}

Knowledge of the heat flow is very important for understanding the thermal and geologic evolution of a planetary body. There are not direct measurements for Mars, but heat flows have been deduced for diverse Martian regions from the effective elastic thickness of the lithosphere (Ruiz et al., 2009) or from the depth to the brittle-ductile transition beneath large thrust faults (Nahm et al., 2011). So deduced heat flows are valid for the time when the lithosphere was loaded or faulted, permitting us to delineate, in a first approximation, the thermal evolution of the planet (Ruiz et al., 2002, 2004; Philips et al., 2001).

\section{4-3- Volcanic activities and topographic formation on Mars}

The effect of heat from lava, volcanic activities and release of thermal energy can be considerable. The topography may be a function of temperature. Several morphologies in Martian features are proglacial and periglacial features, relatively small circular depressions, gullies, fan-deltas, eolian streaks, and diluvial dunes (Pacifici, 2009). Volcanism is a principal way that planets release their internal heat. Volcanic eruptions produce distinctive landforms and rock types that reveal the chemical composition, thermal state, and history of a planet interior. As magma rises and cools, it undergoes many complex compositional changes. The interaction of ice with molten rock can produce distinct landforms. Lava flowing over water- saturated ground can cause the water to erupt violently in an explosion of steam producing small volcano-like landforms (Hauber, 2009). Outflow channels and valleys consistently show higher thermal inertias than the surrounding terrain. Generally, correlations between spatial variations in thermal inertia and geologic features suggest a relationship between the hundred-meter-scale morphology and the centimeter-scale surface layer (Mellon et al., 2000; Hauber, 2009).

\section{4-4- Geothermal}

Heat of Geothermal is more than Volcanism?

The possibilities for use of geothermal energy on Mars have been studied by many scientists (Hauber, 2009). Solar thermal, nuclear fusion, photo-voltaic, wind, solar power satellite and also geothermal energy have been introduced as the possibility for utilization of energy. As we see all these cases are somehow related to heat energy. Mouginis Mark (1990) studied the fluidcut channels in Northwest Tharsis of Mars and suggested that their origin might be o the erosion action of flowing water, rather than lava (Fogg, r1996, Hauber, 2009; Ruiz et al, 2008, 2006). Because some types of energy such as biomass energy, fossil fuel, hydrothermal and tidal energy do not exist on Mars, some other types such as geothermal energy can be a good alternative. (1) Heat in Mars is very important and an issue could be how to exploit geothermal resources. Fogg (1996) discussed the utility of geothermal energy on Mars and also made strong argument for the practicality of such an application. (2) Theoretical studies and RS observations suggest that Mars has a good potential for geothermal resources. (3) Geothermal resources have a good potential to contribute to the energy needs of settlement on Mars.

\section{4-5- Ice and Liquid Water}

How much discover of stable water depends on temperature? The surface materials have a wide range of albedo and thermal inertia. Paige (1992) pointed out that the areas with lower thermal inertia have a wider daily range of surface temperatures. When talking about the effect of planet's obliquity on ice stability, we must note that this effect is also directly related to solar insulation and Mars surface temperature. (1) Temperature plays a main role in discovering the stable liquid water. (2) Temperature is also very important when we want to find out the relationship between the atmospheric pressure and the state of water.

\section{4-6- Reciprocal effect of Ice and Volcanic}

How much is the reciprocal effect of Ice and volcanic? The surface temperatures of Earth and Mars depend on (a) the amount of energy that they receive from the sun and (b) the composition of their atmospheres. Very thin atmosphere of Mars allows the solar heat to escape easily. The temperature and liquid water are two main limiting factors for life on Mars. So it is better to discuss solid ice in one hand and volcanic as the hot phase on the other. On Earth, glacial and per glacial features are common in areas of cold climate. On Mars, the present temperature is appropriate for permafrost, and the presence of water is suspected from data relating to the out gassing of the planet, from RS measurements, and from recognition of fluvial morphology. Morphological studies show features that can be attributed to the action of ice (Pacifici, 2009).

\section{4-7- Soil formation}


Soil formation in the Earth is a function of the some variables including climate, parent materials, time, and relief. In soil formation for Earth, temperature is not considered as independent variable but its role has been considered in some other factors including climate, and time.

\section{4-8- Diurnal surface and subsurface temperature}

The temporal dynamics of Land Surface Temperatures (LSTs) have been predicted over ground terrains (Ruiz et al., 2006), observed over urban areas (Chudnovsky et al., 2004), and modeled by satellite images (Göttsche \& Olesen, 2001). The temporal cycle affects the LST dynamics and, as a result, the TSP. For example, the effectiveness of using emissivity as a kernel depends greatly on the time of day when multiple factors including albedo, shading, and thermal inertia control the radiative temperature (Nichol, 2009), but it is less appropriate in nighttime or winters.

\section{4-9-Wind and erosion}

What is the role of temperature in wind blowing and erosion? The ability of wind to dislodge and move particles around the surface depends on the particles, the atmospheric pressure, the wind speed, and the roughness of the surface (Iverson et al., 1985). The wind blows across the surface develops a turbulent boundary layer in which speed decreases from its free-stream value at high altitudes to a much lower value right at the surface. Dust storms on Mars have been observed for centuries (Kahn et al., 1992). They tend to recur in southern spring and summer. Most are regional in extent, but in some years, as in 1971, they become truly global (Carr, 2007). A question may arise that how is the difference in the role of temperature in wind blowing in Earth and Mars? We may conclude that it is also important to find out the correction coefficient between LST and atmospheric pressure via dramatic rise or drop in surface temperature.

\section{4-10- Evaporation and capillary movement}

Is the deep water available a function of surface temperature? Evaporation from land surface, and its relationship with capillary movement is also related to air and surface temperature. In fact, the interaction of water and lava cause a reciprocal effect of heat on both. The result is not just the release of heat by volcanism, but also its effect on ice, water, and also formation of a table (Pacifici, 2009, Hauber, 2009).

\section{5- TOPICS CRITICAL TO THERMAL RS}

LST is an important parameter highly responsive to the surface energy fluxes and has become valuable to many disciplines. Some common applications of LST on Mars surface involve soil moisture estimation (Ruiz et al., 2004, 2006, 2008, 2009), surface heat monitoring (Liu et al., 2013), studies of hydrological processes, and climate studies (Kustas \& Norman, 2000). Four predetermined assumptions are required in DLST. These include (1) additively, which indicates that the mixture of components is linearly additive, nonlinearly additive, or a reconciliation between linearity and nonlinearity; (2) separability, which indicates whether component temperatures are statistically separable; (3) connectivity, which states the predictability of LSTs through ancillary data such as optical images; and (4) convertibility, which determines whether the spectral, temporal, and angular resolutions of thermal observations can be converted into the spatial resolution of LSTs.

\subsection{Directions for future thermal RS studies}

Although there are some disaggregation of RS LST in terms of the trade off among the temporal, spatial, and spectral resolutions and the difficulties in development, we should provide a review-and-generalization of interdisciplinary literature to have insight on current works and possible directions for future studies. To enhance the progress of thermal $\mathrm{RS}$, the existing spectral, spatial and temporal resolutions are insufficient for more accurate applications. Additionally, as sensor techniques continue to develop, the spatial and spectral resolutions of thermal data should be further improved in the future. At high resolution the thermal elements in a scene may be larger than the resolution cells (Nahm et al., 2013). The main task, then, might be inversely transforming from disaggregation of LST into aggregation (Zhang, et al. 2008).

\subsection{Global warming on Mars}

Over the last 50 years or so, Earth's average temperature has, by some accounts, risen about one degree Fahrenheit. During this same period, has global warming been observed on Mars? The proponents of anthropogenic global warming (AGW) claim that human carbon dioxide emissions are the main cause for recent warming on Earth. I have yet to see any compelling physical evidence to support that hypothesis. There is, however, physical evidence that Earth's temperature and climate are controlled by cyclic changes in the Sun's luminosity and magnetic field. There is also physical evidence that Earth's global temperature and climate are related to the Earth's position relative to the sun. These cycles induce atmospheric oscillations that affect our weather and global temperature, and ultimately climate cycles.

On Mars, sand (62.5- $2000 \mu$ ) has the particle size most easily mobilized at threshold friction velocities and most likely to saltate (Iverson, 1985); it is also the size inferred from thermal infrared observations for most of the Martian dunes (Edgett and Christensen, 1991). However, based on Viking Infrared Thermal Mapper data, Herkenhoff and Vasavada (1999) proposed that north polar dunes consists of grains smaller than sand (Paige et al. 1994). The hypothesis that north polar dunes are composed of particles finer than sand, has been tested by a direct method that requires no intricate thermal modeling. The presence of sand-sized material was confirmed by thousands of MGS TES emissivity spectra of north polar dunes, including those associated with accurate scarps in the 8-12 $\mu$ (Edgett et al., 2002).

\section{5-3- Thermal Inertia}

Diurnal cycles in the surface temperature are strongly dependent on the thermal and physical properties of the top several centimeters of the "soil." Many factors have an effect on temperature including albedo, dust opacity, and atmospheric pressure, but thermal inertia is the key property in controlling these temperature oscillations. Thermal inertia is defined as a combination of thermal conductivity, density, and heat capacity. It represents the ability of the subsurface to conduct and store heat energy away from the surface during the day and to return that to the surface through night. Understanding the thermal inertia of a surface can help identify the small-scale characteristics of that surface. Therefore, both global and local mapping of thermal inertia provides insight into the physical 
characteristic of surface. A great deal can be learned about the nature of the martian surface from correlations between thermal inertia and other data sets. An interesting correlation has previously been observed by Viking data when compared thermal inertia with albedo (Mellon et al., 2000).

\section{5-4- Detailed Emissivity map}

Differences in thermal inertia, reflectance, and emissivity of various materials and different atmospheric radiance are important factors that modify the measured surface temperatures. What about the emissivity of Mars materials in comparison with Earth? The maximum and minimum daily temperatures and their differences (DT) increase with a decrease in reflectance of solar insulation. From these sets of curves, we learn that natural surface materials show considerable modifications in radiant temperatures. The thermal and volatile evolution of Mars has important implications for the production of the Martian crust, relaxation of Martian topographic features, evolution of elastic thickness, and generation of the magnetic field by several models for the thermal evolution (Lillis, 2009).

\section{5- 5- Thermal conductivity and material types}

Thermal conductivity is a measure of the rate at which heat passes through a material. Thermal conductivity of soil depends on soil physical properties such as soil particles, air, moisture and porosity. Thermal capacity determines that how well a material stores heat. Cementing of soil grains can affect the thermal inertia by increasing the efficiency of heat conduction between individual grains by forming or enlarging the contact area. Indurations of the surface layer have been observed at the Viking and Pathfinder landing sites (Moore et al. 1999) and may be widespread (Jakosky et al., 2001, Christensen and Moore 1992). Salt has been suggested as a cementing agent due to the high concentrations of sulfur and chlorine in the soil at these same locations (Moore et al. 1999). It has also been suggested that the degree of indurations could account for much of the variations in thermal inertia observed outside the lowest thermal inertia regions (Jakosky et al., 2001 Christensen and Moore 1992; Lillis, 2009).

\section{5-6-Indices for rocks, minerals and Ice detection}

Defining some indices based on some correlations such as soil line in desert or soil line in Mars surface can be a good foundation for a better understanding in some surface features and also for defining some new land properties indices. With the average recorded temperature of $63 \mathrm{C}(-81 \mathrm{~F})$ and maximum of $20 \mathrm{C}(68 \mathrm{~F})$ and a minimum of $-140 \mathrm{C}(-220 \mathrm{~F})$, how the contribution of heat in surface phenomena on Mars can be revealed? As we know Life on Mars requires water and food from soil. In Mars, both are present but optimum temperature does not exist! If the optimum temperature is prepared, soil can be evolved and ice changed into liquid. What about air temperature? How the heat can affect air temperature? Even differentiation among types of ices (carbon dioxide, methane, water, ammonia) with distinct frost point temperature is possible by using surface temperature.

\section{6- GENERAL CONCLUSION}

We may generally conclude that a more complete understanding of the relationship between thermal inertia, particle size, environment condition, and etc. is very essential to the studies about Mars and other planets. The study has argued of heat as an important control both in the recent centuries, entitled thermal energy or thermal infrared energy, and in the past, entitled fire. There exist no place, no material, no time and no action and reaction that are independent of the heat. By this indicator it would be easier to study many features and phenomena in astronomic and RS researches. The heat is as an indicator that can help detect behaviors of all processes in the world.

\section{References}

Alavi Panah, S.K., De Dapper, M., Goossens, R. and Massoudi, M., 2001, The use of TM thermal band for land cover land use mapping in two different environmental conditions of Iran. J. Agr. Sci. Tech. 3, 331-340

Alavipanah, S.K., 2002, Application of remote sensing in earth science (soil science), University of Tehran Press

Alavipanah, 2007, Thermal remote sensing and its application in earth sciences, University of Tehran Press

Alavipanah, 2009, New principles in remote sensing and interpretation of satellite images and photogrametry, University of Tehran Press

Guest, A., Smrekar, Suzanne E., 1Jet Propulsion Laboratory, California Institute of Technology, 4800 Oak Grove Dr., MS 183-501, Pasadena, CA 91106, USA

Bello, David (2009). "Global Warming Reverses Long-Term Arctic Cooling". Scientific American, Retrieved 8 June 2011

Carr, M.H (2007). Mars: Surface and Interior in Encyclopedia of the Solar System, 2nd ed., McFadden, L.-A. et al. Eds. Elsevier: San Diego, CA, p.319-321

Chapman, M.G.; Smellie, J.L. (2007), Mars Interior Layered Deposits and Terrestrial Sub-Ice Volcanoes Compared: Observations and Interpretations of Similar Geomorphic Characteristics, in The Geology of Mars: Evidence from EarthBased Analogs, Chapman, M., Ed; Cambridge University Press: Cambridge UK, pp. 178-207.

Christensen, P. R., and H. J. Moore 1992, The martian surface layer in Mars, Univ. Arizona Press, Tucson.

Chudnovsky, A., Ben-Dor, E., \& Saaroni, H. (2004), Diurnal thermal behavior of selected urban objects using remote sensing measurements, Energy and Buildings, 36, 1063-1074.

Deans, J. G. schithals and L. J. Carter, 2001, An analysis of thermal imaging method for lanmine detection using microwave heating, Journal of Applied Geophisics 47, 123-133

Deppipo, R., 2008, Binary cycle power plants, In: Geothermal power plants. $2^{\text {nd }}$ edn ch. 8, pp 157-190

Edgett, K. S. and P. R. Christensen, 1991, The particle size of martian aeolian dunes, Journal of Geophysical Research 78, 22765-22776

Duarte, 2003, The physics of Multiple-Prism Optics, Chapter 4, Tunable Laser Optics, 57-74

Fagents, F.A.; Thordarson, T. (2007). Rootless Volcanic Cones in Iceland and on Mars, in The Geology of Mars: Evidence from Earth-Based Analogs, Chapman, M., Ed; Cambridge University Press: Cambridge UK, pp. 151-177.

Fogg, M.J., 1996.The utility of Geothermal energy on Mars. J British Interplanetary Soc. 49 403-422

Göttsche, F. M., \& Olesen, F. S. (2001). Modeling of diurnal cycles of brightness temperature extracted from METEOSAT data. Remote Sensing of Environment 76, 337-348

Ghahroudi, M.; Sadough, S. H.; Nezammahalleh, M. A.; Nezammahalleh, S. K., Multi-criteria evaluation to select sites for ecotourism facilities, case study: Miankaleh Peninsula, Anatolia 23, 373-394

Hauber, E.; Bleacher, J.; Gwinner, K., Williams, D.; Greeley, R., The topography and morphology of low shields and associated landforms of plains Volcanism in the Tharsis Region 
of the Mars, Journal of Volcanology and Geothermal Research $185,69-95$

Herkenhoff and Vasavada (1999), Dark material in the polar layered deposits dunes on Mars, Journal of Geophysical Research 104 (E7), 16487-16500

Iverson, J. D., 1985. Wind as a Geological Processes on Earth, Mars, Venus and Titan. Cambridge: Cambridge University Press.

Jensen, John R., 2005, Introductory Digital Image Processing, 3rdEd., Upper Saddle River, NJ: Prentice Hall, 526

Jensen, John R., 2007, Remote Sensing of the Environment: An Earth Resource Perspective, 2nd Ed., Upper Saddle River, NJ: PrenticeHall, 592

Kahn, R. A., Martin, T. Z., Zurek, R. W. and Lee, S. W., 1992, The marin dust cycle IN Mars, ed., H. H. Kiefer, B. M., Jakosky, C. W. Synder and M. S. Mathewis. Tucson: University of Arizona Press, pp. 1017-1053

Kaufman, D.; Schneider, D.; McKay, N.; Ammann, C.; Bradley, R.; Briffa, K.; Miller, G.; Otto-Bliesner, B. et al. (2009), "Recent warming reverses long-term arctic cooling". Science 325, 1236-1239

Edgett, Kenneth S., Rebecca M. E., Williams, Michael C. Malin, Bruce A. Cantor, and Peter C. Thomas. 2002. Mars landscape evolution: Influence of stratigraphy on geomorphology in the north polar region, GEOMORPHOLOGY 52, 289-297

Kustas, W. P., \& Norman, J. M. (1999), Evaluation of soil and vegetation heat flux predictions using a simple two-source model with radiometric temperatures for partial canopy cover. Agricultural and Forest Meteorology, 94(1), 13-29

Kustas, W. P., \& Norman, J. M. (2000a), A two-source energy balance approach using directional radiometric temperature observations for sparse canopy covered surfaces. Agronomy Journal, 92(5), 847-854

Lillis, R.J.; Dufek, J.; Bleacher, J.E.; Manga, M., 2009, Demagnetization of crust by magnetic intrusion near the Arsia Mons volcano: Magnetic and thermal implications for the development of the Tharsis Province, Mars, Journal of Volcanology and Geothermal Research 185, 123-138

Liu, James Voogt, Xiaolin Zhu, Jinling Quan, Jing Li (2013), Disaggregation of remotely sensed land surface temperature: Literature survey, taxonomy, issues, and caveats. Jounal of Remote Sensing of Environment 131 (2013) 119

Mann, M.; Zhang, Z.; Hughes, M.; Bradley, R.; Miller, S.; Rutherford, S.; Ni, F. (2008), "Proxy-based reconstructions of hemispheric and global surface temperature variations over the past two millennia", Proceedings of the National Academy of Sciences of the United States of America 105, 13252-13257

Marchant, D.; Head, J.W., 2007, Antarctic dry valleys: microclimate zonation, variable geomorphic processes, and implications for assessing climate change on Mars, Icarus 192, 187-222

Mellon, Michael T., Bruce M. Jakosky, Hugh H. Kieffer and Philip R. Christensen, 2000, High-Resolution Thermal Inertia Mapping from the Mars Global Surveyor Thermal Emission Spectrometer, Icarus 148, 437-455

Mollon, M. T., Jakosky, B. M., Kieffer H.H., and Christensen, P. R., 2000, High resolution thermal inertia mapping from the
Mars Global surveying thermal emission spectrometer. Icarus $148,437-455$

Moore, H. J., D. B. Bickler, J. A. Crisp, H. J. Eisen, J. A. Gensler, A. F. C. Haldemann, J. R. Matijevic, L. K. Reid, and F. Pavlics, 1999, Soil-like deposits observed by Sojourner, the Pathfinder rover. J. Geophys. Res. 104, 8729-8746

Mouginis Mark, P. J., (1990), Recent water release in the Tarsis region of Mars, Icareus 84, 362

Nahm, A. L., Schultz, R.A., 2011, Magnitude of global contraction on Mars from analysis of surface faults: implications for martian thermal history, Icarus 211, 389-400

Nash, R., 2003, progress at school: Pedagogy and care for knowledge, Teaching and Teacher Education 19, 755-767

Nichol, J. (2009), An emissivity modulation method for spatial enhancement of thermal satellite images in urban heat island analysis, Photogrammetric Engineering and Remote Sensing, 75(5), 547-556

Pacifici, A., 2009, The Argentinean Patagonia and the Martian landscape, Planetary and Space Science 57, 571-578

Phillips, R. J.; Zuber, MT; Solomon, SC; Golombek, MP; Jakosky, BM; Banerdt, WB; Smith, DE; Williams, RM et al. (2001). "Ancient Geodynamics and Global-Scale Hydrology on Mars", Science 291 (5513), 2587

Putzig, N.E., Mellon, M. T., Kretke, K. A. Arvidson, R.E., 2005. Global thermal inertia and surface properties of Mars from the MGS mapping mission 2005, Jcarus 173, 325-341 Ruiz, J., Fairén, A.G., Dohm, J.M., Tejero, R., 2004, Thermal isostacy and deformation of possible paleoshorelines on Mars, Planet, Space Sci. 52, 1297-1301

Ruiz, J., Fernndez, C., Gomez-Ortiz, D., Dohm, J.M., Lopez, V., Tejero, R., 2008, Ancient heat flow, crustal thickness, and lithospheric mantle rheology in the Amenthes region, Mars, Earth Planet, Sci. Lett. 270, 1-12

Ruiz, J., McGovern, P.J., Tejero, R., 2006, The early thermal and magnetic state of the cratered highlands of Mars, Earth Planet, Sci. Lett. 241, 2-10

Ruiz, J., Williams, J.P., Dohm, J.M., FernJndez, C., Lepez, V., 2009. Ancient heat flows and crustal thickness at Warrego rise, Thaumasia Highlands, Mars: Implications for a stratified crust

Solomon, Sean C.; Head, James W. (1982), "Evolution of the Tharsis Province of Mars: The Importance of Heterogeneous Lithospheric Thickness and Volcanic Construction". J. Geophys. Res. 87 (B12): 9755-9774

Sun, L.; Sun, R.; Li, X.; Liang, S.; Zhang, R., 2012, Monitoring surface soil moisture status based on remotely sensed surface temperature and vegetation index information, Agricultural and Forest Meteorology 166, 175-187

Wilson, L. (2007), Planetary Volcanism in Encyclopedia of the Solar System, McFadden, L.A. et al., Eds., Academic Press, San Diego, CA, p. 829

Zhang, L.; Ninomiya, Y.; Yamashita, T., 2006, formation of submicron particulate matter (PM) during coal combustion and influence of reaction temperature, Fuel 85, 1446-1457 